\title{
Eixos de integração e desenvolvimento, Rota de Integração Latino-Americana e turismo: território de Mato Grosso do Sul e franjas fronteiriças
}

\author{
Axes of integration and development, Route of Latin American Integration and \\ Tourism: Mato Grosso do Sul territory and frontier frances
Ejes de integración y desarrollo, Ruta de Integración Latinoamericana y turismo: territorio de Mato Grosso del Sur y franjas fronterizas

\author{
Cleonice Alexandre Le Bourlegat ${ }^{1}$ \\ Recebido em 11/12/2018; revisado e aprovado em 12/03/2019; aceito em 26/04/2019 \\ DOI: http://dx.doi.org/10.20435/inter.v20iespecial.2532
}

\begin{abstract}
Resumo: O objetivo do presente artigo é abordar a concepção de corredores de transporte e Eixo de Integração e Desenvolvimento (EID), que permitam melhor refletir sobre o papel da "Rota de Integração Latino-Americana (RILA)", à qual Mato Grosso do Sul se insere, assim como sobre a contribuição da atividade turística, no desenvolvimento territorial do EID em construção na América do Sul, envolvendo Brasil, Paraguai, Argentina e Chile. A pesquisa é natureza bibliográfica e documental, além de incluir informações obtidas por meio da experiência direta dos pesquisadores nessa parceria, pela UCDB no "Conselho de Reitores de Instituições de Ensino Superior no Estado - CRIE/MS". O texto aborda a construção conceitual do EID relacionado ao corredor logístico de transporte, assim como a posição estratégica de Mato Grosso do Sul frente aos vários corredores logísticos bioceânicos, projetados na iniciativa da IIRSA. Nesse modelo sistêmico de construção territorial do EID, são feitas reflexões sobre um processo de planejamento integrado de turismo, como atividade complementar, no fortalecimento dessa modalidade de construção territorial multinacional no continente sul-americano.
\end{abstract}

Palavras-chave: rota de integração; eixo de integração e desenvolvimento; atividade turística

Abstract: The objective is to approach the conception of transport corridors and Integration and Development Axis (EID), to reflect more accurately on the role of "Latin American Integration Route (RILA)", to which Mato Grosso do Sul is inserted, as well as on the contribution of the tourist activity, in the territorial development of the IDA under construction in South America, involving Brazil, Paraguay, Argentina and Chile. The research is of bibliographical and documentary nature, besides including information obtained through the direct experience of the researchers in this partnership, by UCDB on the "Council of Rectors of Institutions of Higher Education in the State-CRIE/MS". The text approach the conceptual construction of the IDA related to the logistics logistic corridor, as well as the strategic position of Mato Grosso do Sul in front of the various bioceanic logistic corridors, projected at IIRSA's initiative. In this systemic model of territorial construction of IDA, reflections are made on an integrated tourism planning process, as a complementary activity, in the strengthening of this type of multinational territorial construction in the South American continent.

Keywords: integration and development axis; latin american integration route; tourism.

Resumen: El objetivo del presente artículo es abordar la concepción de corredores de transporte y Eje de Integración y Desarrollo (EID), que permitan mejor reflexionar sobre el papel de la "Ruta de Integración Latinoamericana (RILA)", a la que se inserta Mato Grosso do Sul, así como sobre la contribución de la actividad turística, en el desarrollo territorial del EID en construcción en América del Sur, involucrando a Brasil, Paraguay, Argentina y Chile. La investigación es naturaleza bibliográfica y documental, además de incluir informaciones obtenidas a través de la experiencia directa de los investigadores en esa asociación, por la UCDB en el "Consejo de Rectores de Instituciones de Enseñanza Superior en el Estado- CRIE/MS". EI texto aborda la construcción conceptual del EID relacionado al corredor logístico de transporte, así como la posición estratégica de Mato Grosso do Sul frente a los varios corredores logísticos bioceánicos, proyectados en la iniciativa de la IIRSA. En este modelo sistémico de construcción territorial del EID, se hacen reflexiones sobre un proceso de planificación integrada de turismo, como actividad complementaria, en el fortalecimiento de esa modalidad de construcción territorial multinacional en el continente sudamericano.

Palabras clave: ruta de integración; eje de integración y desarrollo; actividad turística.

\footnotetext{
${ }^{1}$ Universidade Católica Dom Bosco, UCDB, Campo Grande, Mato Grosso do Sul, Brasil
} 


\section{INTRODUÇÃO}

O presente artigo tem como objetivo abordar a concepção de corredores de transporte e Eixo de Integração e Desenvolvimento (EID), que permitam melhor refletir sobre o papel da "Rota de Integração Latino-Americana (RILA)", recentemente aprovada pelos quatro países nela envolvidos (Brasil, Paraguai, Argentina e Chile) e em processo de implementação, no qual Mato Grosso do Sul se insere, assim como sobre a contribuição da atividade turística, no desenvolvimento territorial do EID em construção na América do Sul.

A Rota de Integração Latino-Americana deve partir de Campo Grande, em Mato Grosso do Sul, em direção aos portos do Norte chileno de Antofogasta a lquique, passando pelo Chaco paraguaio e pelo Noroeste argentino. Em princípio, a RILA faz parte do Corredor Rodoviário Bioceânico, anteriormente projetado para ligar essa área do continente também aos portos do Pacífico. O interesse nuclear por essa ligação de Mato Grosso do Sul aos portos do Pacífico tem sido a logística de acesso para o escoamento de produtos agrícolas de exportação, de modo mais rápido e com menor custo, especialmente para atingir os mercados asiáticos.

A finalidade dessa reflexão, portanto, é verificar como o turismo integrado pode contribuir como atividade complementar, nessa construção territorial de nível multinacional, entre Mato Grosso do Sul e as franjas fronteiriças dos quatro países, por meio do efeito estruturante da RILA.

A pesquisa que deu origem ao artigo é de natureza bibliográfica e documental, além de incluir informações obtidas por meio da experiência direta dos pesquisadores nesse processo de construção territorial multinacional, como integrantes do Conselho de Reitores de Instituições de Ensino Superior no Estado (CRIE/MS) e pela Universidade Católica Dom Bosco (UCDB).

O texto foi organizado em quatro partes, além dessa introdução e considerações finais. Na primeira, foi abordada a construção conceitual relacionada ao Eixo de Integração e Desenvolvimento, por meio de políticas públicas, partindo-se da concepção original de Corredor de Transporte. A segunda parte apresenta as formas de inserção de Mato Grosso do Sul nos Eixos de Integração e Desenvolvimento, no Zicosul e nos corredores logísticos de transporte e energia. Já na terceira parte, busca-se mais especificamente descrever a posição estratégica de Mato Grosso do Sul frente aos corredores logísticos rodoviários bioceânicos previstos pela iniciativa da Integração da Infraestrutura Regional Sul-Americana (IIRSA), assim como a respeito da aprovação da RILA. Por fim, são colocadas reflexões básicas a respeito do processo de um planejamento integrado do turismo, estruturado por influência da RILA e com apoio das localidades urbanas mais dinâmicas.

\section{DO CORREDOR DE TRANSPORTE AO EIXO DE INTEGRAÇÃO E DESENVOLVIMENTO: ASPECTOS CONCEITUAIS}

A concepção de "corredor de transporte" foi prevista como política pública no Brasil, no I Plano Nacional de Desenvolvimento (PND) (1972-74), durante os governos militares, abordado como um conjunto coordenado de infraestrutura viária e de outros recursos, necessários ao funcionamento do transporte (GEIPOT, 1996). Tratava-se, nesse início, de uma concepção de corredor, ainda linear, cuja finalidade era, sobretudo, a de viabilizar a movimentação de grandes quantidades de mercadorias, de suas origens aos destinos previstos, favorecendo a exportação agrícola. Voltava-se, especialmente, a garantir rentabilidade adequada aos produtos agrícolas, 
estando associada a políticas de modernização dos portos, armazenamento de grãos, entre outros serviços. Os corredores de transporte do Centro-Sul do país, em especial, foram destinados ao transporte de produtos agrícolas voltados aos portos de Santos e Paranaguá, contemplando grande parte de Mato Grosso do Sul (GARDIN, 2008).

Em meados dos anos de 1980 e até a década seguinte, durante os governos neoliberais de Fernando Collor de Mello e Fernando Henrique Cardoso, o modelo anterior de "corredor de transporte" passou a se ressentir dos impactos da falta de recursos, e, desse modo, repensado em novas bases, ou seja, como "corredor logístico de transporte", proposto ao Brasil e estendido para o continente sul-americano, valendo-se do exemplo europeu (THORSTENSEN, 2016). A nova estratégia passou a ser a de corredores de transporte capazes de favorecer maior agilidade na integração buscada entre fornecedores, produtores e consumidores, por meio de combinações multimodais. A finalidade era favorecer a integração de diferentes porções do território desse continente ao mercado internacional, proporcionando diferentes fluxos de carga e informações entre os locais de origem e de destino. As vias dominantes de alta capacidade deveriam constituir o principal núcleo e suporte dessa rede, devendo correr em paralelo ou se entrecruzarem nesse emaranhado de fluxos para ser adensado. O adensamento, conforme afirmou Couto (2013), deveria ser induzido por meio de projetos distribuídos territorialmente. No conjunto, os diferentes modais precisariam manter conexões em rede ininterruptas, contribuindo para a construção de regiões integradas (TAVARES, 2016). Na definição dos corredores considerados núcleo de rede, levar-se-ia em conta a identificação de áreas urbanas que pudessem assumir o papel grandes nós desses fluxos dinâmicos. Também seriam eleitos para esse fim, os postos de fronteira mais relevantes em cada país envolvido.

A lógica econômica de integração territorial passou a se basear na acessibilidade logística dessa rede emaranhada aos vários pontos da área de influência do corredor. O conjunto induzido de atividades econômicas estruturadas e conectadas às vias principais, deveria gerar efeitos multiplicadores em sua área de influência (LEMOS, 2004). Cada região de potencialidades a serem dinamizadas, vinculadas a um setor produtivo ou a uma vantagem de localização passaria a constituir um Eixo de Integração e Desenvolvimento- EID (LE BOURLEGAT; OLIVEIRA, 2010). Os projetos locais e sub-regionais partiriam de ações estratégicas e integradas, a serem propagadas na região e no país.

No Brasil, segundo Castillo (2011), os Eixos Nacionais de Integração e Desenvolvimento já passaram a constar dos PPA de 1996-99 e 2000-03, durante o governo Fernando Henrique Cardoso, em continuidade à política anterior dos "corredores de exportação". A principal finalidade era viabilizar a circulação de bens e produtos de maior valor e competitividade em cada região, no caso as commodities, mediante distribuição mais rápida e eficaz, de modo a contribuir para a redução do "custo Brasil" para essa natureza de produtos de exportação.

A Iniciativa para a Integração da Infraestrutura Regional Sul-Americana, baseada em eixos de integração e desenvolvimento, conforme lembram Fernandes e Diniz Filho (2017), emergiu no Brasil em agosto de 2000, após o "Primeiro Encontro de Presidentes da América do Sul", ocorrido em Brasília, envolvendo 12 países (Argentina, Bolívia, Brasil, Chile, Colômbia, Equador, Guiana, Paraguai, Peru, Suriname, Uruguai e Venezuela). Tais Eixos de Integração e desenvolvimento foram lançados de forma concomitante aos ENID. A finalidade foi promover um esforço conjunto, na implementação das infraestruturas relacionadas à ideia de "corredor logístico de transporte", no sentido de proporcionar a integração territorial, tanto no Brasil 
como nas franjas de fronteira com os doze países parceiros. De acordo com Nogueira (2008), foi proposta a integração física regional de EID, por meio de projetos de infraestrutura em transporte, energia e comunicação.

Para esse fim, segundo Nogueira (2008), propôs-se uma visão estratégica de integração dos doze países sul-americanos envolvidos, visando a um desenvolvimento coerente e sustentável, que permitisse maior inserção no mercado internacional. Nesse contexto, passaram a ser delimitados os dez EID, baseados em características comuns das realidades entre países. Nesse processo, no lugar de integrar as regiões a partir de suas particularidades, passou-se a levar em conta como cada uma delas poderia participar de um projeto de desenvolvimento comum. Em 2000, por meio da lirsa foram propostos para o continente sul-americano doze Eixos de Integração e Desenvolvimento, modificados em 2003 para apenas dez EID, ou sejam: Andino, Andino do Sul, Capricórnio, Hidrovia Paraguai-Paraná, Amazonas, Escudo Guianês, do Sul, Interoceânico Central, Peru-Brasil-Bolívia e Mercosul-Chile. Cada EID deveria, em princípio, ser estruturado, de modo a viabilizar o fluxo de bens, serviços, pessoas e informações no âmbito dos doze países envolvidos na lirsa, em torno de projetos comuns. Os processos setoriais de integração deveriam ocorrer a partir de pequenos grupos, com potencial para desenvolver ações conjuntas nos setores contemplados pela lirsa (NOGUEIRA, 2018).

Visto assim, os EID foram considerados espaços definidos por fluxos de bens e serviços entre regiões produtoras. Em princípio, os dez EIDs deveriam facilitar o acesso a zonas de alto potencial produtivo, que ainda permanecessem isoladas ou subutilizadas. Poderiam se manifestar tanto em mercados já bastante expressivos, como naqueles em que as vocações e as potencialidades regionais se apresentassem latentes. Em outros termos, a regionalização seria construída por meio de fluxos comerciais dentro da região, como também fora dela, quando esta apresentasse territórios com potencial para gerar produtos exportáveis.

Nessa abordagem, os EIDs propostos, delimitados por grandes vias de infraestrutura, ficaram sobrepostos e foram classificados, segundo Souza e Silveira (2014), de acordo com os fluxos já existentes, em duas modalidades: (1) "eixos com dinâmica de integração preestabelecidos" para os territórios de mercados bem expressivos; (2) "eixos emergentes" para os territórios com potencialidade de crescimento. As iniciativas de regionalização seriam impulsionadas por meio de um portfólio de projetos considerados relevantes, propagados de forma integrada por meio de redes de cooperação (FERNANDES; DINIZ FILHO, 2017).

Das obras de infraestrutura previstas no EID, conforme lembra Couto (2013), também poderiam fariam parte instalações portuárias, aeroportos, terminais de carga e descarga, estocagem e manuseio, hidrovias, rodovias e ferrovias, redes de cabos, sistemas de fibra ótica, redes elétricas, sistemas de água e esgoto, oleodutos, entre outros. A proposição desses suportes de infraestrutura levou em conta o princípio colocado por Harvey (2003), de que os fixos deveriam contribuir para estimular os fluxos. Por seu turno, os fluxos contribuiriam para reduzir o tempo de deslocamento e os custos de transporte, na superação de grandes distâncias.

No ano de 2008, durante o governo Lula, foi criada a União de Nações Sul-Americanas (Unasul), com a tentativa de consolidar esse processo de integração regional. Para esse fim, foram constituídos no mesmo ano, doze conselhos setoriais, entre os quais o Conselho SulAmericano de Infraestrutura e Planejamento (Cosiplan), ao qual foi incorporada a lirsa. A inexistência ou precariedade de infraestrutura física adequada passou a ser vista como um entrave na dinamização do EID. A finalidade desse conselho foi redefinir a matriz de projetos 
existentes e priorizar aqueles considerados mais importantes para fortalecimento e integração da infraestrutura regional, assim como procurar fontes de financiamento para os projetos priorizados.

No âmbito da Cosiplan, também ocorreram novas mudanças relacionadas à concepção dos eixos de integração e desenvolvimento e na sua visão estratégica. Conforme afirmam Souza e Silveira (2014), na infraestrutura dos EIDs, foi dada ênfase ao transporte, energia e comunicação, para atuarem de forma sinérgica na condução dos processos de integração e desenvolvimento. Em sua área de influência, dever-se-iam identificar as cidades mais adensadas e dinâmicas, consideradas os nós da rede regional, com potencial para induzir e a ela se integrar novas redes de interconexões e interdependências. Nesse sentido, tanto o corredor como as cidades-nós passariam a exercer o papel estruturante dos vetores territoriais de desenvolvimento. Tratava-se, nesse caso, de uma visão de desenvolvimento territorial, portanto, de concepção mais sistêmica e holística, que deveria levar em conta como vetor de desenvolvimento sustentável, não só a dimensão econômica, mas também a social e ambiental.

Esse processo de regionalização em rede, de modelo sistêmico e holístico, veio substituir o anterior modelo de polarização hierarquizado de cidades. No anterior, preconizado por François Perroux (1977), as forças se distribuíam da cidade polo para a periferia, reservando-se à primeira o comando e à periferia uma situação de relativa dependência. O modelo sistêmico e holístico, por seu turno, teria potencial para gerar um campo de forças sinérgicas, resultante de fluxos de ida e de vinda, que se combinariam e se retroalimentariam continuamente, de modo a fortalecer e proporcionar maior autonomia relacional a todos os integrantes do território regionalizado.

No modelo sistêmico, a estruturação territorial das redes de cooperação dar-se-ia desde a escala local e microrregional até a multinacional, com a participação de diferentes partes interessadas (stakeholders) locais, regionais e do âmbito dos países envolvidos. Na revisão estabelecida pelo BNDES para o PPA 2004-2007, essas escalas territoriais já começaram a ser consideradas. Na macroescala estava a "franja multinacional de território", enquanto que na escala microeconômica foi apontada aquela relativa ao cluster (MANZONI NETO, 2013). É preciso salientar que o conceito correspondente de cluster mais adotado pelas políticas públicas brasileiras e pelo próprio BNDES tenha sido, de fato, o do Arranjo ou Sistema Produtivo Local, que privilegia a aprendizagem coletiva dos stakeholders. De acordo com Lastres e Cassiolato (2005), tais arranjos organizados em escala micro territorial supõe um conjunto de agentes econômicos, políticos e sociais, no desenvolvimento de atividades econômicas correlatas, com vínculos expressivos de produção, interação, cooperação e aprendizagem. Incluem tanto produtores quanto fornecedores, comercializadores, clientes, associações, cooperativas, certificadoras, organizações de formação, treinamento e pesquisa, desenvolvimento e engenharia, promoção e financiamento, entre outros.

Nesse novo modelo de desenvolvimento territorial, passou a ser exaltado o papel da construção de governanças, fruto da articulação dos interessados envolvidos (públicos e privados) no seu planejamento, mediante disponibilização transparente de informações. Nesse processo, como se pode observar, a lógica organizacional deveria ocorrer, tanto de cima para baixo como debaixo para cima, de modo a se valorizar o território e dotá-lo de maior autonomia e responsabilidade no processo de desenvolvimento.

As funções estruturadoras dos vetores de desenvolvimento territorial seriam dirigidas por planos, programas e projetos (TAVARES, 2016). Desse modo, em 2011, os ministros integrantes 
do Cosiplan aprovaram no âmbito da IIRSA uma Agenda de API (531 projetos), considerados estruturantes, relativos ao transporte, energia e comunicação, com potencial para promover a conectividade regional e gerar desenvolvimento econômico e social sustentável (UNASUR/ COSIPLAN, 2011). Os projetos passariam a ser elaborados, portanto, com base nas potencialidades econômica, social e ambiental, específicas de cada área de influência, visando a sustentabilidade dessas três dimensões. Nesse caso, o objetivo dos programas territoriais de integração voltar-se-iam para a identificação e implementação de um conjunto de ações complementares aos projetos prioritários.

Em 2012, também foi constituído no âmbito da Unasul o Conselho de Ministros do Turismo. Na primeira reunião ocorrida em 2013, segundo De Pieri (2018), foi possível identificar que 60\% do turismo desenvolvido no continente era intrarregional, com várias deficiências nas conexões terrestres, marítimas e aéreas entre os países. Em 2014, envolvendo ainda um acordo com os Ministérios da Cultura, foi assinada a Declaração sobre o "Turismo Comunitário", tendo sido constituído um grupo de trabalho, com a finalidade de harmonizar conceitos e metodologias e impulsionar projetos de cooperação.

\section{INSERÇÃO DE MATO GROSSO DO SUL NOS EIXOS DE INTEGRAÇÃO E DESENVOLVIMENTO}

Dada a posição estratégica no centro do continente, Mato Grosso do Sul ficou inserido na superposição de pelo menos três dos Eixos de Integração e Desenvolvimento, durante a criação da IIRSA: (1) Eixo Interoceânico Central: (2) Eixo da Hidrovia Paraguai-Paraná: (3) Eixo de Capricórnio (Figura 1). Ao aderir ao Conselho de Desenvolvimento do Extremo Sul (Codesul), em 1992, que envolve os estados do Paraná, Santa Catarina e Rio Grande do Sul, o Mato Grosso do Sul também acabou por se inserir nas ações do "Eixo Mercosul-Chile", conforme lembra Gardin (2008), num interesse comum pelo escoamento de suas commodities pelo Porto de Paranaguá. 
Figura 1 - Dez Eixos de Integração e Desenvolvimento propostos na IIRSA

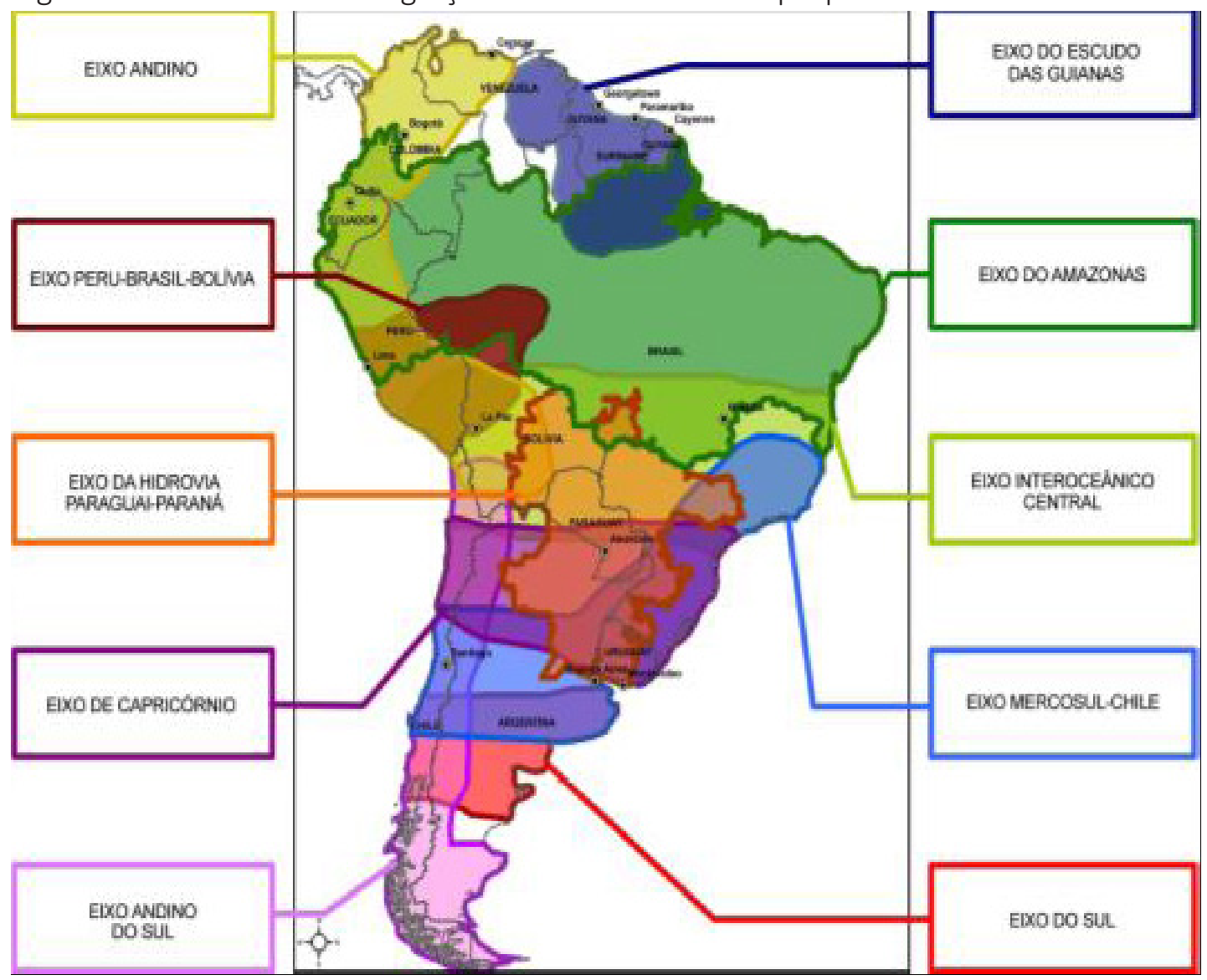

Fonte: Geosur, 2015.

É preciso salientar que, nessa iniciativa de construção dos corredores logísticos de transporte, o Mato Grosso do Sul já se posicionava numa trama multimodal de transporte, tendo sido contemplado com obras dos projetos priorizados no PPA 1996-99. Foram previstas nessa época, por exemplo, a construção da Ferronorte, as obras de conclusão da hidrovia Tietê-Paraná, a pavimentação da BR 163. Na infraestrutura de energia, em 1999 passaram a funcionar as três primeiras unidades da UHE do Porto Primavera e o gasoduto Bolívia-Brasil, este construído a partir do Pacto de La Paz, entre 1997 e 1999. 
Figura 2 - Obras previstas no Programa Avança Brasil 1996-99

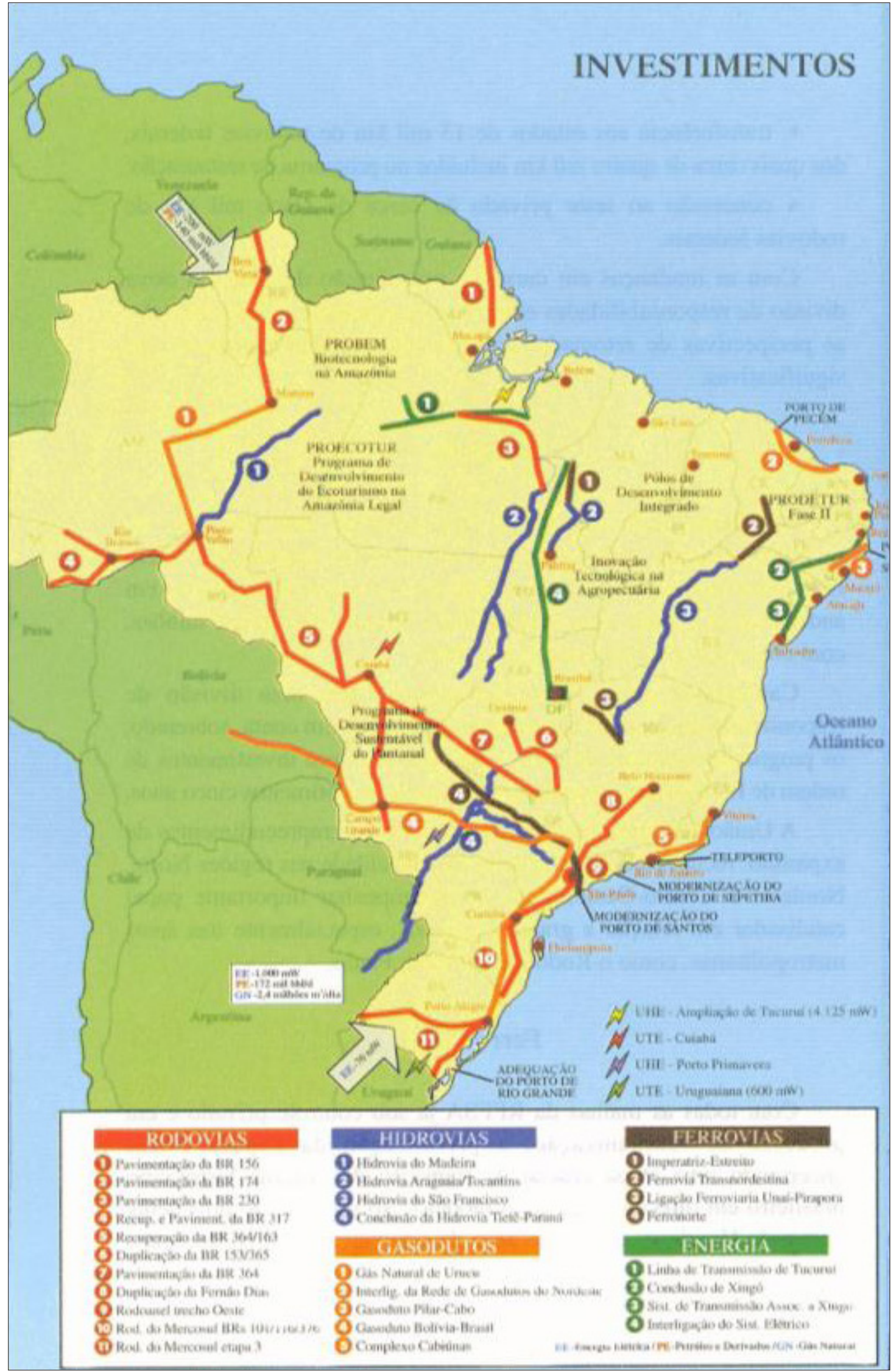

Fonte: Programa Avança Brasil, Fernando Henrique Cardoso, 2008. 
Tal posicionamento poderia proporcionar diversas oportunidades de integração, seja com os países vizinhos (inclusive os do Mercosul), seja com os de fora do continente, mediante acesso aos portos do Atlântico e Pacífico.

Em 1997, o Mato Grosso do Sul aderiu ao projeto Zona de Integração do Centro Oeste da América do Sul (Zicosul), existente desde 1974, sob a iniciativa dos membros do Grupo Empresario Inter-regional del Centro Oeste Sudamericano (Geicos), do Noroeste argentino (Salta, Jujuy e Tucuman) e do Norte do Chile (Tarapacá, Antofogasta, Copiapó), sul da Bolívia e do Peru, Paraguai, os estados do Centro-Oeste do Brasil e de Santa Catarina (Figura 3). Constituído por empresários e universidades, o objetivo do GEICOS tem sido o de promover um processo de integração sub-regional (produtiva, social, cultural), favorável a sua inserção internacional competitiva, especialmente junto ao mercado asiático. Essa sub-região foi proposta para integrar o EID de Capricornio.

Figura 3 - Zona de Integração do Centro-Oeste da América do Sul

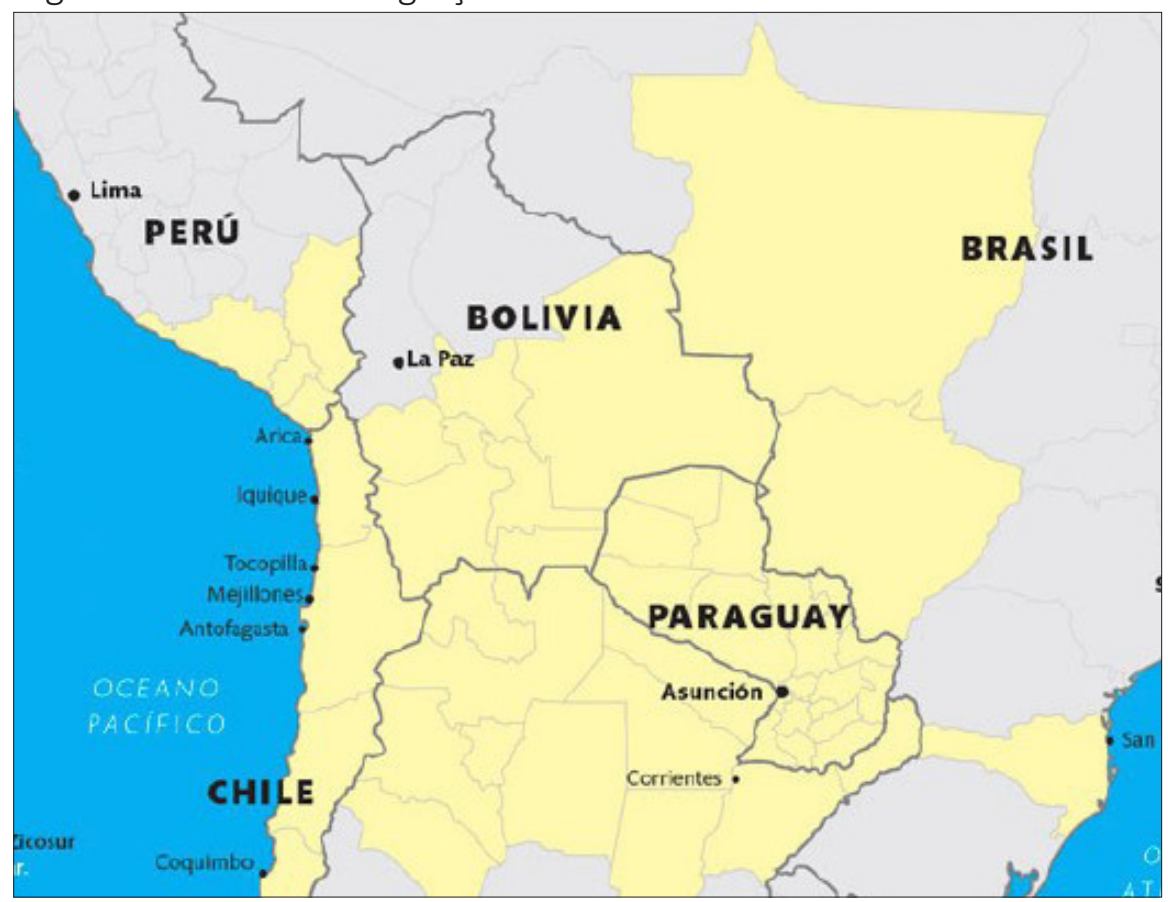

Fonte: Zicosul, 2018

\section{CORREDORES RODOVIÁRIOS DE EXPORTAÇÃO EM MATO GROSSO DO SUL}

No âmbito do Zicosul e do EID de Capricórnio, segundo Oliveira (2010), chegaram a ser propostos três corredores rodoviários bioceânicos, que deveriam passar por Mato Grosso do Sul. O primeiro, "Corredor Norte", sairia de Arica no Chile, vindo pela Bolívia (La Paz, Santa Cruz de La Sierra, Puerto Suares), chegando a Mato Grosso do Sul por Corumbá, para daí atravessar o Estado em direção ao porto de Santos no estado de São Paulo.

O segundo, chamado de "Corredor de Capricórnio", sairia opcionalmente de um dos 3 portos chilenos (Antofogasta, Mejilones e Tocopila/lquique), passando ainda nesse país por Calama e São Pedro de Atacama, para em seguida cruzar a Argentina (Paso de Jama, Jujuy, Tartagal) e o Paraguai (Pozo Hondo, Mariscal Estigarribia, Filadelfia, Carmelo Peralta), entrando em Mato Grosso do Sul por Porto Murtinho e Campo Grande, para seguir em direção ao estado de São 
Paulo. A esse segundo corredor dever-se-ia conectar ainda por caminho secundário a Bolívia (Tarija e Potosi), podendo atingir a Colômbia e a Venezuela.

O terceiro seria o "Corredor do Sul" que, em princípio, partiria de um dos 3 portos chilenos (Antofogasta, Tocopilla, Mejilones), passando por Calama, para adentrar a Argentina (Paso de Sico, Salta, Metan, Resistência, Clorinda), atravessando o Paraguai (Assunción, Concepción), para entrar em Mato Grosso do Sul por Ponta Porã, passando por Dourados, para daí atingir o estado de São Paulo.

Pelas proposições da lirsa, no âmbito do Eixo Interoceânico Central, dois corredores rodoviários de exportação deveriam atingir o Mato Grosso do Sul. O primeiro sairia mais ao Norte, elegendo dois portos peruanos (Matarani e llo) e dois portos chilenos (Arica e lquique) como opção de saída ou entrada no continente, para atravessar o território boliviano, atingindo Mato Grosso do Sul por Corumbá. Passaria, então, por Miranda, Aquidauana, Campo Grande, Três Lagoas e daí para o porto paulista. O segundo corredor sairia do porto de lquique no Chile, entrando em terras bolivianas mais ao Sul do primeiro, para adentrar o Paraguai em Pozo Hondo até Carmelo Peralta ou então Pedro Juan Cabalero, atingindo Mato Grosso do Sul, respectivamente por Porto Murtinho ou Ponta Porã. Dessas duas portas de entrada, o corredor avançaria até Campo Grande para se combinar com o corredor anterior até São Paulo.

Por seu turno, os empresários e governo sul-mato-grossenses, empenhados no esforço de redução do "custo Brasil" a seus produtos de exportação, não se sentiram plenamente contemplados com as obras rodoviárias previstas nos PPA para os EID, uma vez que a única obra proposta pela IIRSA dizia respeito à recuperação da rodovia BR-163. Por outro lado, conforme Oliveira (2010), a consciência da posição estratégica ocupada pelo Estado no centro do continente e dos EID, em relação aos portos do Atlântico e do Pacífico, assim como aos países do Mercosul, conduziu ao grande interesse na concretização estratégica dos corredores logísticos de exportação, sejam rodoviário, ferroviário e hidroviário.

Logo após a adesão de Mato Grosso do Sul ao Zicosul, em 1997, foram desencadeados estudos pelos órgãos governamentais desse Estado, no sentido de verificar a viabilidade da logística do "Corredor de Capricórnio" em direção aos portos chilenos, passando por Porto Murtinho, terras paraguaias e Noroeste argentino. Convencidos da importância desse corredor, já em 1997, houve a iniciativa governamental para concretizar o asfaltamento da rodovia que liga Campo Grande a Porto Murtinho, embora o término dessa obra tenha se efetivado somente em 2003. Por seu turno, também o Paraguai já havia concordado com a iniciativa de implantação de uma rodovia, ligando Porto Murtinho a Filadélfia. O maior desafio se dava em relação à construção da ponte na travessia do rio Paraguai, ligando Porto Murtinho a Carmelo Peralta.

No entanto, esse corredor rodoviário só entrou na pauta da reunião dos presidentes do Brasil, Argentina, Chile e Paraguai em 2015, quando foi assinada a "Declaração de Assunção", ocasião em que se criou um Grupo de Trabalho, coordenado pelas chancelarias dos quatro países, encarregado de criar subsídios para as discussões com os envolvidos, de modo a promover sua implantação.

Em 2016, além do acordo estabelecido entre Brasil e Paraguai para a construção da ponte rodoviária internacional sobre o rio Paraguai, passaram a ser realizados encontros e seminários locais, sob o incentivo do Grupo de Trabalho, para se discutir o planejamento e implementar a rota Porto Murtinho-Portos Norte do Chile, envolvendo, governo, empresários e universidades. Em nível governamental, acordo com o governo do estado de Mato Grosso do Sul (2018), o 
norte chileno demonstrou forte interesse em ativar as plataformas logísticas junto aos portos de exportação.

O Noroeste argentino vislumbrou os benefícios do Plano Belgrano do governo federal, voltado ao desenvolvimento de sua infraestrutura (rodoviária, ferroviária e aérea), com a finalidade de integrar essa parte do território argentino, especialmente em função dos altos níveis de produtividade que se deram recentemente na agricultura. No Paraguai, a passagem do corredor foi vista como uma forma de melhoria da infraestrutura para integrar o Chaco ao resto do país e aos portos.

Já em Mato Grosso do Sul, o maior interesse foi em relação ao agronegócio, no tocante ao encurtamento das distâncias aos mercados asiáticos, por meio dos portos do Pacífico, como também para promover importação direta de insumos a preços mais competitivos. Em relação ao empresariado sul-mato-grossense, em 2017 foi organizada em Campo Grande, a expedição Rota da Integração Latino-Americana, para atingir Antofogasta por meio da rota rodoviária proposta. Dela participaram cerca de 90 pessoas, entre elas integrantes do governo, do setor agrícola e transporte, de universidades, da imprensa. No tocante às universidades de Mato Grosso do Sul, sob incentivo do representante do Grupo de Trabalho do Ministério das Relações Exteriores do Brasil, no mesmo ano, foi constituído o Conselho de Reitores de Instituições de Ensino Superior no Estado (Criems). Formado por representantes das instituições públicas e privadas, o Crie passou a ter como objetivo discutir o processo de construção do território do Eixo de Integração e Desenvolvimento, a ser estruturado pela logística do corredor rodoviário em processo de implantação. Por meio desse Conselho e facilitado pelo GT, as universidades envolvidas vêm buscando formas de trabalho de parceria em rede com as universidades do Chile, Argentina e Paraguai que aderiram a essa iniciativa, por meio de seminários presenciais e via Internet.

Em 2018, no Brasil houve a promulgação do acordo firmado em 2016 para a construção da ponte entre Brasil e Paraguai, bem com recursos financeiros provenientes da Itaipu Binacional.

\section{TURISMO NA CONSTRUÇÃO DO TERRITÓRIO DO EIXO DE INTEGRAÇÃO E DESENVOLVIMENTO}

Durante as reuniões mantidas no âmbito da rede de universidades de origem brasileira, argentina, chilena e paraguaia, comprometidas com a construção de um programa territorial do Eixo de Integração e Desenvolvimento, mediante efetivação do Corredor Rodoviário, sob incentivo do GT dos quatro países, o turismo foi identificado como o primeiro setor a ser incentivado para se construir ações integradas complementares aos projetos prioritários.

Têm sido vários os estudos que demonstram o papel complementar que o turismo pode exercer na economia local e regional. Entre outros, Souza, Santos e Thomé-Ortiz (2015), demonstraram essa complementaridade em atividades rurais desenvolvidas em algumas localidades do Rio Grande do Sul. A atividade turística nesse caso, favoreceu, não só o complemento da renda, como a ampliação de oportunidades de emprego e a fixação do jovem no campo. Também Salgado, Viana e Aragão (2014) em seus estudos, confirmaram o uso de uma infinidade de serviços (hospedagem, alimentação, deslocamento, entre outros) que o turista usa durante o passeio, gerando grande potencialidade na geração de empregos diretos, indiretos e sazonais.

O turismo, durante a implantação dos projetos da lirsa, já se mostrou uma atividade sensível à instalação das infraestruturas dos corredores logísticos de exportação e que, deveria ser 
estimulado (FERNANDES; DINIZ FILHO, 2017). Essa atividade tende a ser revelar como: (1) uma prática econômica complementar que favorece a inclusão das comunidades locais; (2) uma prática social que favorece o encontro e a troca; (3) uma prática cultural que favorece a interculturalidade e o sentimento de pertença; (4) uma prática ambiental, na medida em se age em prol da conservação do ambiente natural e construído produzido, seja como fruto da oferta ou como fruto do consumo. De fato, além de contribuir para complementar as atividades econômicas, identificadas como nucleares na dinamização dos Eixos de Integração e Desenvolvimento, o turismo propicia processos econômicos inclusivos na sociedade. Também proporciona uma dinâmica social, proporcionada pelo encontro entre pessoas de diferentes culturas, numa vivência direta da realidade visitada (ARAUJO, 2013). A aproximação das pessoas e dos povos favorece a compreensão das diferentes maneiras de ser e estar no mundo, desencadeando transformações nas representações sociais dos envolvidos (PEREIRA; LOPES, 2013). Ao contribuir para um maior reconhecimento da diversidade cultural, o turismo também reforça a coesão social, além de favorecer um modo de governança mais democrática no território (UNESCO, 2009). Como prática cultural, pode-se afirmar que o diálogo entre saberes, práticas e simbologias culturalmente distintas, proporcionado pelo turismo, contribui para se atribuir um novo sentido a elas, num universo multi e intercultural. O encontro e a oportunidade de vivenciar o diferente e o incomum ao seu cotidiano, contribui para fomentar no visitante um sentimento de inclusão nesse mundo (MELO, 2005). Desse modo, essa atividade pode favorecer a construção de um sentimento de identidade coletiva, entre os integrantes da região em processo de construção.

As estratégias de integração e desenvolvimento em redes de cooperação, são estabelecidas em cada EID, tanto "de baixo para cima" (bottom-up), como "de cima para baixo"(top down), desde que se consiga construir ações de coordenação ou governança apropriadas a cada situação. Mesmo que acordos e planos governamentais sejam construídos em nível do EID, portanto, "de cima para baixo", estratégias de integração e desenvolvimento precisam ser estabelecidas "de baixo para cima" (bottom-up), por meio de redes de cooperação, na área de influência do Corredor Bioceânico e dos polos urbanos mais dinâmicos. Desse processo resultam diversos micro e mesoterritórios articulados no contexto macroterritorial do EID, sejam em nível local e regional. O suporte ativo dos integrantes das comunidades locais em processos de desenvolvimento e gestão do turismo, num respeito a seus direitos e desejos, conforme afirmam Soares, Emmendoerfer e Monteiro (2013), promovem o sucesso do desenvolvimento sustentável da atividade promovida, em cooperação com os órgãos governamentais. Barquero (2002) lembra que processos participativos e de governança exigem o envolvimento e comprometimento das partes interessadas locais, num respeito às suas decisões, sejam no poder de delegar, como também nas responsabilidades assumidas no processo de gestão. Minari e Rabinovic (2014) admitem que esse processo constitui, de fato, um grande desafio, uma vez que suscita diálogo, aprendizagem social e empoderamento comunitário.

As articulações estratégicas que brotam "de baixo para cima", com base na conjugação de um ou mais partes interessadas, visam aumentar seu nível de desempenho, podendo se manifestar de várias formas e níveis de cooperação (EIRIZ, 2001). Construída em nível local, essa articulação pode ganhar uma amplitude, tanto horizontal como vertical, e ampliar a escala territorial de organização.

A horizontalidade dessa articulação implica relações de cooperação estabelecidas entre partes interessadas (stakeholders) que atuam no mesmo ramo de atividade, como é o caso do 
turismo, ou especificamente no ecoturismo, turismo rural, turismo gastronômico, entre outros. Tais territórios podem se constituir em simples aglomerações dos envolvidos em determinadas localidades para o exercício de determinadas atividades, chamada por Porter de cluster. Mas esse conjunto pode ganhar maior complexidade, ao atrair o suporte de outras organizações interessadas, sejam de natureza privada, governamental e não-governamental, universidades, órgãos técnicos e de pesquisa, certificadoras, entre outras. Nesse caso, tem sido nominado em políticas públicas brasileiras de "arranjo ou sistema produtivo local" (CASSIOLATO; LASTRES (2005). Por meio das redes de cooperação, num processo de construção social, as partes interessadas se empenham na reinvenção de seus territórios de ação (DEMATTEIS; GOVERNA, 2005). No turismo, por exemplo, pode-se construir numa mesma lógica sistêmica de integração, por iniciativa das partes interessadas, os chamados "roteiros integrados", mediante planejamento participativo e articulado entre localidades que apresentam similaridades paisagísticas ou culturais, valorizando-se em cada uma das suas potencialidades específicas. Vários outros arranjos sistêmicos podem emergir da iniciativa local e regional das partes interessadas. Diferentes arranjos complexos e diferenciados ainda podem se conectar entre si de forma complementar, adensando o território de maior complexidade e entrelaçamentos.

A verticalidade dessa cooperação implica encadeamento produtivo das partes interessadas que atuam em diferentes atividades específicas do mesmo setor turístico (empresários de agências de viagem, atrativos, hotéis, restaurantes, transportes, guias, entre outros). A cadeia produtiva, nesse caso, resulta da interdependência de uma crescente divisão de trabalho entre agentes econômicos do mesmo setor (PROCHNIK, 2001). O encadeamento desses "circuitos espaciais de produção" pode se constituir em diversas escalas territoriais, desde a local, regional, nacional e até internacional (SANTOS,1996). Não raro, as operadoras de turismo que divulgam e vendem pacotes turísticos podem se encontrar fora do país.

Tem sido comum essa verticalidade, conhecida como "trade do turismo", ser construída em localidades urbanas mais atrativas e dinâmicas do setor. De acordo com Batalha (1995), as circunstâncias em que cadeias produtivas se manifestam em torno de certos lugares privilegiados, aptos a favorecer sinergias dentro do sistema, são denominadas "operações-nós". Desse modo, mesmo que num dado centro urbano não estejam todos os atrativos turísticos, nele podem se aglomerar e interagir de forma encadeada, entre outros, operadoras de turismo, agências de viagem, guias de turismo, meios de hotelaria, restaurantes e bares, empresas de eventos e de transporte (rodoviário, ferroviário e aeroviário). Dessa cadeia localizada em um mesmo centro urbano ainda podem participar provedores de serviços de interesse turístico, tais como locadoras de veículos, bancos e agências de câmbio, serviços de comunicação e informática, artesãos, entre outros. Não raro, também fazem parte dessa cadeia os órgãos de suporte ao turismo, tais como organizações de pesquisa e formação profissional, órgãos governamentais (municipais, estaduais, federais), agentes creditícios, sociedade civil organizada a exemplo de associações de classe, cooperativas, sindicatos, conselhos setoriais, certificadoras. Nesse caso, horizontalidade e verticalidade se conjugam num mesmo local. Este centro urbano, por sua complexidade dinâmica, passa a exercer uma função estruturante na região, especificamente em localidades em que ocorram iniciativas de receptivo para atrativos turísticos ou que servem de suporte às viagens aos mesmos e com as quais se estabeleçam elos de cooperação.

Uma das propriedades das redes de cooperação, sejam horizontais ou verticais, é a inovação, manifestada quando ocorre trocas de saberes e de competências entre seus integrantes 
(LUNDVALL, 2001). Segundo o autor, inexiste empresa individual que domine todas as competências necessárias para promover inovações. No caso de redes de cooperação, ela depende em grande parte do aprendizado interativo, fruto do esforço coletivo. Nesse processo, a participação das universidades e órgãos de pesquisa exercem papel fundamental, tanto na proposição, como na absorção e uso de novas tecnologias. Como no setor turístico, o cliente é atraído para a fonte de oferta do serviço, também existem possibilidades de trocas entre ele e o fornecedor, na melhoria constante do produto turístico ofertado.

Os elos de cooperação e aprendizagem interativa dependem em grande parte dos arranjos institucionais estabelecidos e do processo de governança territorial, esta concebida, segundo Holec e Brunet-Jolivald (2000), como ação de coordenação entre as partes de diferentes interesses. Não se trata apenas de uma coordenação baseada em um conjunto de regras e normas a seguir e, sim, de um processo que funciona por meio do diálogo, capaz de assegurar e defender a participação de todos em função de seus interesses específicos, voltados a um objetivo comum. Esse ambiente interativo e processo comunicativo propiciam a reflexividade (BATESON, 1986), de modo a ampliar a oportunidade para que cada integrante consiga inovar seus próprios comportamentos e ações.

\section{CONSIDERAÇÕES FINAIS}

As reflexões feitas, relativas aos aspectos conceituais dos corredores logísticos de exportação, de construção mais linear, na indução à construção de territórios multinacionais de forma sistêmica- os Eixos de Integração e Desenvolvimento - e ainda as particularidades que a atividade turística pode exercer nesse processo, permitem algumas considerações finais a respeito.

Mesmo que concebido de forma linear, para viabilizar a movimentação de grandes quantidades de mercadorias, de suas origens aos destinos previstos, é preciso avaliar as condições que a RILA, apoiada pelas cidades mais dinâmicas, reúne para estruturar um território regional multinacional entre Mato Grosso do Sul e suas franjas fronteiriças (Paraguai, Argentina e o Chile).

As vias dominantes de alta capacidade, em paralelo ou entrecruzadas, mediante conexões em rede, podem constituir condições mais favoráveis para estruturar uma região integrada, no sentido de promover seu desenvolvimento. Nesse caso, o território vai sendo construído, por meio de conexões estratégicas de cooperação em rede, estabelecidas entre diferentes partes interessadas, em diversas escalas (local e regional), mediante suporte dos corredores e das cidades-nós (vetores territoriais).

Diferente do modelo anterior de desenvolvimento, baseado na polarização, que gerava centros de comando e áreas dependentes, esse modelo territorial sistêmico de cooperação em rede baseia-se em forças sinérgicas, e por isso apresenta potencial para propiciar maior participação e autonomia a todos os integrantes.

A combinação top-down e bottom-up é estratégica nesse modelo sistêmico, seja para se construir coletivamente um território mais integrado com culturas plurais, como para se estabelecer um sentimento de pertença a ele. Também apresenta potencial para uma dinâmica social de desenvolvimento, com maiores impactos positivos nas dimensões econômicas, sociais e ambientais e ainda na segurança entre os povos nessas "franjas de fronteira". O turismo, por suas características, como se pôde apresentar, é dotado de fortes potencialidades para se iniciar e fortalecer esse processo. 
Por fim, torna-se importante salientar que Mato Grosso do Sul e esse território em construção por efeito estruturante da RILA, em princípio, deve se entrecruzar com o efeitos similares de outros corredores logísticos de transporte, já em processo de pactuação para sua implementação em breve. Pode-se destacar aqui o corredor ferroviário bioceânico, que liga o porto de llo no Peru/Pacífico, passando pela Bolívia, entrando em Mato Grosso do Sul por Corumbá, para atingir o porto de Santos/Atlântico. A esses ainda pode-se somar o projeto de integração elétrica de grande porte entre o Brasil e Bolívia, em pleno processo, além de outros.

Por meio da lógica de integração territorial, baseada na acessibilidade logística de uma rede emaranhada de corredores, o conjunto de atividades induzidas para as respectivas áreas de influência, poderá resultar num leque de efeitos multiplicadores. Eles podem se propagar mediante um conjunto de projetos locais e sub-regionais com ações estratégicas e integradas, de modo a atribuir participação, interação e aprendizagem coletiva, assim como maior autonomia a todos os participantes.

\section{REFERÊNCIAS}

ARAÚJO, D. F. Educação superior, turismo e interculturalidade: um novo olhar da educação para uma nova cultura. In: ARAÚJO, M. I. O (Org.). Perspectivas de educação ambiental no constructo da interculturalidade. Aracaju: Criação, 2013. p. 37-50.

BARQUERO, A. V. Desenvolvimento endógeno em tempos de globalização. Porto Alegre: UFRGS Editora, 2002.

BATALHA, M. O. As cadeias de produção agroindustriais: uma perspectiva para o estudo das inovações tecnológicas. Revista de Administração, São Paulo, v. 30, n. 42, p. 43-50, 1995.

BATESON, G. Mente e natureza: uma unidade necessária. Rio de Janeiro: Francisco Alves, 1986.

CASTILLO, R. Agricultura globalizada e logística nos cerrados brasileiros. In: Circulação, transportes e logística: diferentes perspectivas. SILVEIRA, M. R. (Org.). São Paulo: Outras Expressões, 2011. p. 331-54.

COUTO, L. F. Desenvolvimento, integração e assimetrias: caminhos e descaminhos da aproximação regional na América do Sul. Brasília: Fundação João Mangabeira, 2013.

DEMATTEIS, G.; GOVERNA, F. Territorio y territorialidad en el desarrollo local: la contribución del modelo SLOT. Boletín de la A.G.E, n. 39, p. 31-58, 2005.

DE PIERI, V. S. G. Turismo e integração regional: um pouco na América Latina e Caribe. Boa Vista: Editora da UFR, 2018.

EIRIZ, V. Proposta de tipologia sobre alianças estratégicas. Revista de Administração Contemporânea, v. 5, n. 2, p. 65-90, maio/ago. 2001.

FERNANDES, M. S.; DINIZ FILHO, L. L. Planejamento territorial da IIRSA: conceitos e projetos. Revista de Geopolítica, v. 8, n. 1, p. 1-18, jan./jun. 2017.

GARDIN, C. Mato Grosso do Sul: considerações sobre política de transporte e projetos de integração continental. In: LAMOSO, Lisandra (Org.). Transportes e politicas públicas em mato Grosso do Sul. Dourados: UFGD, 2008. p. 77-91.

GEIPOT. Estudo de Corredores Bioceânicos. Brasília: Ministério dos Transportes, 1996. 
HARVEY, D. The New Imperialism. Oxford: Oxford University Press, 2003.

HOLEC, N.; BRUNET-JOLIVALD, G. De la gouvernance des économies à celle des territoires: note de synthèse sur la gouvernance. Centre de documentation de l'urbanisme, 2000.

LASTRES, H. M. M.; CASSIOLATO, J. E. Glossário de arranjos e sistemas produtivos e inovativos locais. Rio de Janeiro: Redesist/UFRJ, 2005.

LE BOURLEGAT, C. A.; OLIVEIRA, M. C. Politicas públicas e mapeamento de APLs em Mato Grosso do Sul. In: CAMPOS, R. R et al. Políticas estaduais para Arranjos Produtivos Locais no Sul, Sudeste e Centro-Oeste do Brasil. Rio de Janeiro: E-Papers, 2010. p. 291-334.

LEMOS, M. B. Regionalização: análise da experiência brasileira recente. Relatório do projeto "Diretrizes para formulação de politicas de desenvolvimento regional e de ordenação do território brasileiro". Belo Horizonte: Cedeplar/UFMG, 2004.

LUNDVALL, B. A. Políticas de Inovação na Economia do Aprendizado. Parcerias Estratégicas, n. 10, p. 200-18, mar. 2001.

MANZONI NETO, A. Abordagem territorial no planejamento público federal no Brasil a partir dos anos 1990: uma análise da atuação de empresas de consultoria. GEOUSP-Espaço e Tempo, São Paulo, n. 34, número especial, p. 106-18, 2013.

MELO, C. Concepção de um sistema de apoio à decisão aplicado à gestão do investimento em turismo. Lisboa: ITP, 2005. (Coleção Temas de Turismo).

MELO, M. J. G. A Inserção do ecoturismo no Brejo de Serra Negra/Bezerros/PE. Uma Proposta de Desenvolvimento Socioespacial? Dissertação (Mestrado em Geografia) - Universidade Federal de Pernambuco, Recife, 2005.

MINARI, M. L.; RABINOVICI, A. Diálogo, participação e projetos de turismo com comunidades em Unidades de Conservação na Amazônia brasileira. Revista Brasileira de Ecoturismo, São Paulo, v. 7, n. 1, p. 44-66, fev./abr. 2014.

NOGUEIRA, J. L. M. Iniciativa para a Integração da Infraestrutura Regional Sul Americana - IIRSA. Análise Integração Regional/Desenvolvimento. Conjuntura Internacional/ Cenários PUC Minas, 2008.

OLIVEIRA, V. de A. A infraestrutura de transportes como politica governamental para o desenvolvimento regional e a integração sul-americana: uma análise sobre as rotas bioceânicas em Mato Grosso do Sul. 2010. Dissertação (Mestrado em Ciências Humanas) - Universidade Federal da Grande Dourados (UFGD), Dourados, MS, 2010.

ORGANIZAÇÃO DAS NAÇÕES UNIDAS PARA A EDUCAÇÃO, A CIÊNCIA E A CULTURA (UNESCO). Relatório Mundial da Unesco: investir na diversidade cultural e no diálogo intercultural. Paris, 2009.

PEREIRA, A. S.; LOPES, S. D. A influência da cooperação estratégica no processo de desenvolvimento do turismo de Natal (RN): análise de relações entre os stakeholders. Revista Brasileira de Estratégia, Curitiba, v. 6, n. 2, p. 137-50, maio/ago. 2013.

PERROUX, F. O conceito de polo de crescimento. In: FAISSOL, E. (Org). Urbanização e regionalização. Secretaria de Planejamento da Presidência da República, 1977.

PROCHNIK, Victor. Cadeias produtivas na politica de ciência, tecnologia e inovação. Rio de Janeiro: UFRJ, 2001. 
SALGADO, T. R.; VIANA, J. L. R,; ARAGÃO, A. R. S. Impactos da atividade turística à economia municipal de Alto Paraíso de Goiás, Brasil. Mercator, Fortaleza, v. 13, n. 3, p. 75-91, set./dez. 2014.

SANTOS, M. A natureza do espaço. Técnica e tempo. Razão e Emoção. São Paulo: Hucitec, 1996.

SOARES, É. B. S.; EMMENDOERFER, M. L.;. MONTEIRO, L. P. Gestão pública no turismo e o desenvolvimento de destinos turísticos em um estado da Federação Brasileira: uma análise do planejamento estratégico do turismo em Minas Gerais (2007-2010). Tourism \& Management Studies, v., 9, n. 2, p. 50-6, 2013.

SOUZA, R. L.; SANTOS, E. O.; THOMÉ-ORTIZ, H. O turismo no espaço rural como atividade complementar de geração de renda e ocupação não agrícola no Corede das Hortênsias do Estado do Rio Grande do Sul, Brasil. Caderno Virtual de Turismo. Rio de Janeiro, v. 17, n. 1, p. 171-86, abr. 2017.

SOUZA, V. H. P; SILVEIRA, M. R. Integração territorial na América do Sul: uma análise dos projetos de infraestrutura dos portfólios da IIRSA/COSIPLAN. Cadernos Prolam/USP, v. 13, n. 25, p. 137-56, 2014.

TAVARES, J. C. Eixos: novo paradigma do planejamento regional? Os eixos de infraestrutura nos PPA's nacionais, na IIRSA e na macrometrópole paulista. Cadernos Metrópole, São Paulo, v. 18, n. 37, p. 67195, set./dez. 2016.

THORSTENSEN, V. Corredores logísticos multimodais, desenvolvimento de redes transeuropeias de transporte e implantação: do conceito do corredor no Brasil. São Paulo: Diálogos Setoriais União Europeia/ Brasil, 2016.

UNASUR-COSIPLAN. Cartera de Proyectos. 2011. Disponível em: www.iirsa.org. Acesso em: 1o jan. 2012.

UNASUR/COSIPLAN. Agenda de Projetos Prioritários-API. IIRSA, nov. 2011.

\section{Sobre a autora:}

Cleonice Alexandre Le Bourlegat - Doutora em Geografia (Desenvolvimento Regional) pela UNESP-Presidente Prudente. Mestre em Geografia (Geografia Humana-Urbana) pela Universidade de São Paulo. Graduação em Geografia pela UNESP. Diretora Acadêmica no Brasil e docente do Master Internacional Erasmus Mundus oferecido pelo consórcio entre Universidade de Pádua/ Itália, Universidade Sorbonne Paris 1, Universidade de Leuven / Bélgica e UCDB / Brasil. Professora convidada e bolsista da União Europeia na Universidade Paris 1 Pantheon-Sorbonne. Docente no Mestrado em Desenvolvimento Local e Assessora de Relações Internacionais da Universidade Católica Dom Bosco. Pesquisadora da Rede de Pesquisa em Sistemas Produtivos e Inovativos Locais (REDESIST - UFRJ). Atua principalmente com os temas: Desenvolvimento Territorial, Desenvolvimento Local/Regional, geografia urbana, e Sistema/Arranjo Produtivo Local. E-mail: cleonice@lebourlegat.net, Orcid: http://orcid.org/0000-0003-0814-0334 
